\title{
Diagnosis of acute canine leptospirosis using multiple laboratory tests and characterization of the isolated strains
}

\author{
Bruno Alonso Miotto', Barbara Furlan Tozzi', Manoela de Souza Penteado', Aline Gil Alves Guilloux², \\ Luisa Zanolli Moreno², Marcos Bryan Heinemann ${ }^{2 *}$, Andrea Micke Moreno², Walter Lilenbaum ${ }^{3}$ \\ and Mitika Kuribayashi Hagiwara' ${ }^{1}$
}

\begin{abstract}
Background: Dogs presenting with acute leptospirosis may present non-specific clinical and laboratory findings, and the definitive diagnosis may require additional confirmatory tests, including bacterial culture, for the direct or indirect identification of the pathogen. The present study describes the diagnosis of leptospirosis in suspected dogs based on the use of multiple diagnostic tests, including serological, molecular and bacteriological tests, along with the characterization of the recovered leptospiral strains.

Results: Urine, serum and blood samples were collected from 33 dogs with suspected clinical leptospirosis treated at the University of São Paulo Veterinary Hospital Service (Hovet FMVZ-USP) between 2013 and 2016. Only dogs with high blood urea nitrogen and creatinine levels in association with multiple clinical manifestations of the disease were included. Leptospiral culture, PCR and serology (Microscopic agglutination test - MAT) were performed in blood and urine samples taken from all suspected dogs at clinical presentation, and an additional prospective MAT titration was performed in seven dogs. Infection could be identified exclusively by PCR in 10 dogs (30.3\%), exclusively by MAT in four dogs (12.1\%) and by both tests in four dogs, totaling 18 dogs (54.5-95\%Cl: 37.6-71.5). Six out of eight MAT-confirmed cases presented with the highest titers against the Icterohaemorrhagiae serogroup. Leptospires were recovered from urine samples from two PCR-positive dogs, and both strains could be characterized by Multilocus Sequence Analysis and serogrouping as L. interrogans serogroup Icterohaemorrhagiae. Both isolates were shown to be pathogenic in the hamster model.

Conclusions: The simultaneous use of MAT and PCR was able to increase the diagnosis of leptospirosis in clinically suspected cases. Despite the increasing incidence of new serovars affecting dogs being reported in different locations, our results suggest that leptospiral strains belonging to the Icterohaemorrhagiae serogroup are still a major causative agent of canine leptospirosis in São Paulo, Brazil.
\end{abstract}

Keywords: Leptospirosis, Dogs, Canine, PCR, MAT, Acute infection, Culture, Sequencing, MLST, Icterohaemorrhagiae

\footnotetext{
* Correspondence: marcosbryan@usp.br

${ }^{2}$ Departamento de Medicina Veterinária Preventiva e Saúde Animal

(Department of Veterinary Preventive Medicine and Animal Health),

Faculdade de Medicina Veterinária e Zootecnia (School of Veterinary

Medicine and Animal Science), Universidade de São Paulo (University of São

Paulo), São Paulo, SP 05508-270, Brazil

Full list of author information is available at the end of the article
}

(c) The Author(s). 2018 Open Access This article is distributed under the terms of the Creative Commons Attribution 4.0 International License (http://creativecommons.org/licenses/by/4.0/), which permits unrestricted use, distribution, and reproduction in any medium, provided you give appropriate credit to the original author(s) and the source, provide a link to the Creative Commons license, and indicate if changes were made. The Creative Commons Public Domain Dedication waiver (http://creativecommons.org/publicdomain/zero/1.0/) applies to the data made available in this article, unless otherwise stated. 


\section{Background}

Leptospirosis is a bacterial disease caused by infection with pathogenic species of the genus Leptospira, which can affect virtually all mammals [1]. Dogs are considered highly susceptible to the infection because of a marked environmental exposure to leptospires, and canine leptospirosis has been largely described worldwide [1, 2]. Recent reports have shown the reemergence of clinical illness in dogs and humans [1,3], highlighting the importance of improving current diagnostic approaches and prevention strategies.

Infected dogs may manifest a broad spectrum of clinical symptoms, varying from hepatic and renal failure, often accompanied by hemorrhagic and pulmonary disorders, to mild, self-limiting febrile illness and asymptomatic infections [4]. Clinical and laboratory findings are usually non-specific, and a definitive diagnosis requires additional confirmatory tests for the direct or indirect identification of the pathogen, such as dark-field microscopy, Polymerase Chain Reaction (PCR), bacterial culture and Microscopic agglutination test (MAT) [1].

Since the exact time of infection at clinical presentation is typically unknown, and given that the early and accurate identification of infected dogs is crucial to alter the course of the disease with appropriate drug therapy [5], the use of multiple simultaneous tests may improve the chance for a correct diagnosis and consequent therapeutic success [6]. Despite the development of several serological tests for the detection of anti-Leptospira antibodies in recent years [7-9], the MAT is still widely employed for the serodiagnosis of acute leptospiral infection [10]. However, critical limitations may hamper its use in a clinical setting; the evaluation of one single MAT test may fail to detect antibodies at the early phase of the disease, and titration of convalescent serum samples is frequently required to reveal seroconversion, which may impose some diagnostic difficulties due to the high mortality of the disease. MAT also has a poor ability to predict the infecting serovar and may not distinguish between infection and vaccine-induced titers [10].

Conversely, PCR has been successfully used to confirm leptospiral infection at the early stages of infection $[6,11]$, and sequencing PCR amplification products has enabled the identification of the different leptospiral species infecting dogs $[12,13]$. Nonetheless, culturing leptospires still stands as the gold standard reference test to unmistakably confirm leptospiral infection, and only serological characterization of the isolated strains may provide reliable information regarding serogroup or serovar identity [1]. The establishment of a panel of leptospiral strains circulating among dog populations remains the major strategy to support the development and commercialization of vaccines with more specific serovar composition, which would hypothetically increase immunization effectiveness for local canine populations. Unfortunately, culture is challenging due to frequent contamination and the fastidious growth of the pathogen [1]. Recovering leptospires from suspected dogs is also limited by the early institution of therapeutic intervention, which is usually required after the disease is suspected [14].

Few reports have studied canine leptospirosis in Brazil [15], and the characterization of leptospiral strains recovered from suspected clinical cases is poorly documented [16]. Given the benefits of using multiple laboratory tests to increase the likelihood of an accurate diagnosis, we hereby describe the diagnosis of leptospirosis in suspected cases treated at a University reference center, based on the association of multiple diagnostic strategies, such as serological, molecular and bacteriological tests, along with the characterization of the recovered leptospiral strains.

\section{Methods}

\section{Sample collection and inclusion criteria}

Urine and blood samples were collected from 33 dogs with suspected clinical leptospirosis presented to the University of São Paulo Veterinary Hospital Service (Hovet FMVZ-USP) between 2013 and 2016. The dogs were suspected of acute leptospirosis when presenting with high serum blood urea nitrogen (BUN) and creatinine levels of unknown origin $(>60 \mathrm{mg} / \mathrm{dL}$ and $1.4 \mathrm{mg} / \mathrm{dL}$, respectively) in association with two or more clinical manifestations suggestive of leptospirosis (hemorrhagic disorders, fever, vomiting, jaundice, prostration, hyporexia/anorexia). Dogs presenting with polyuria, polydipsia and weight loss a month prior to the presentation at the veterinary ambulatory were not included in the study in order to rule out chronic kidney disease bias.

Leptospiral culturing, PCR and MAT were performed in all suspected dogs at clinical presentation, and samples were collected prior to the institution of antimicrobial therapy. Biochemistry and hematological parameters were also determined and included blood urea nitrogen (BUN) and creatinine (CR) serum concentrations, alkaline phosphatase (ALP) and alanine aminotransferase activity (ALT), including also hematocrit (Ht) and white blood cell count (WBC). Reevaluations were performed in seven dogs and included exclusively serum antibody titration and evaluation of biochemistry and hematological parameters; no PCR or bacterial culture was performed in the prospective evaluation.

Blood samples were collected from the jugular or cephalic vein and drawn into BD Vacutainer tubes (BD Diagnostics, New Jersey, USA) and Venosafe ${ }^{\text {ts }}$ tubes containing $\mathrm{K}_{3}$ EDTA (Terumo, Terumo Europe N.V, Leuven, Belgium) to obtain serum and whole-blood samples, respectively. All urine samples were taken aseptically by cystocentesis. 


\section{Diagnostic criteria}

Acute leptospiral infection was confirmed by the detection of at least a four-fold increase in MAT titers between acute and convalescent serum samples [1] and/or the presence of MAT titers $\geq 800$ in single serum samples from non-vaccinated dogs, as previously suggested [5]. Dogs with positive PCR results (urine and/or blood samples) were considered to be infected only after identification of Leptospira spp. was confirmed by DNA sequencing.

\section{Anti-Leptospira antibody detection}

MAT was performed to detect anti-Leptospira antibodies in patient's serum samples [17] using a panel of 22 serovars representing 18 serogroups, as previously described [12]. Endpoint titers were determined using two-fold dilutions until the last well showing 50\% agglutination was recorded. The cut-off for a positive MAT reaction was defined as a titer $\geq 100$; however, only non-vaccinated dogs with single MAT titers of 800 or above were considered to be acutely infected.

\section{Culturing of Leptospira}

For the recovery of leptospires, $0.5 \mathrm{~mL}$ aliquots from blood and urine samples were diluted in sterile physiological solution to a final concentration of $1: 10$ and $1: 100$, and $0.5 \mathrm{~mL}$ of each solution was further inoculated in semi-solid Fletcher and liquid EMJH medium (Difco Laboratories, Franklin Lakes, NJ, USA). The tubes were incubated at $28{ }^{\circ} \mathrm{C}$ for 12 weeks and examined weekly by dark-field microscopy for the presence of spirochetes.

\section{Leptospiral DNA detection}

DNA was extracted from blood or urine samples using NucliSens $^{\bullet}$ miniMAG $^{\mathrm{m}}$ (BioMérieux Inc., Durham, NC, USA) according to the manufacturer's instructions. Urine samples were centrifuged (6.500 G-force, $25{ }^{\circ} \mathrm{C}$, $25 \mathrm{~min}$ ) and pellets were resuspended in $1 \mathrm{ml}$ sterile phosphate-buffered saline (PBS - $\mathrm{pH}$ 7.2) prior to DNA extraction. Extracted DNA was subjected to PCR amplification using a previously reported Leptospira genus-specific protocol and primers targeting a $331 \mathrm{bp}$ fragment of the 16S rRNA gene [18]. Cycling conditions were carried out as follows: $94{ }^{\circ} \mathrm{C}$ for $5 \mathrm{~min}, 40$ cycles at $94{ }^{\circ} \mathrm{C}$ for $30 \mathrm{~s}, 60^{\circ} \mathrm{C}$ for $30 \mathrm{~s}, 72{ }^{\circ} \mathrm{C}$ for $30 \mathrm{~s}$ and a final extension at $72{ }^{\circ} \mathrm{C}$ for $5 \mathrm{~min}$. Pure L. interrogans serovar Canicola (strain Hond Utrecht IV) genomic DNA was used as a positive control and DNase-free water as a negative control in all PCR runs. The amplified products were separated by electrophoresis on a $2 \%$ agarose gel stained with SYBR Safe DNA gel stain (Invitrogen, Thermo Fisher Scientific Inc., Carlsbad, CA, USA) and analyzed under UV transillumination.

\section{S rRNA sequencing}

The amplicons were sequenced on an ABI 7500 Genetic Analyzer (Life Technologies, Waltham, MA, USA). The sequences were edited using BIOEDIT Sequence Alignment Editor 7.0.9 (Hall, 1999 - Ibis Biosciences, Carlsbad, CA, USA) and compared to reference sequences deposited in GenBank using the BLAST tool (http://www.ncbi.nlm.nih. gov/BLAST/).

\section{Characterization of dog isolates Serogrouping}

The serogroups of the isolates were determined by MAT using a panel of rabbit anti-sera for 34 serovars representing 28 serogroups (Andamana, Australis, Autumnalis, Ballum, Bataviae, Canicola, Calledoni, Codice, Cynopteri, Djasiman, Grippotyphosa, Hebdomadis, Holland, Icterohaemorrhagiae, Javanica, Lousiana, Lyme, Manhao, Mini, Panama, Pomona, Pyrogenes, Ranarum, Sarmin, Sejroe, Seramanga, Shermani, and Tarassovi). High rates of agglutination with a particular antiserum were used to identify the presumptive serogroup of the strain [19].

\section{MLST}

Multilocus Sequence Typing (MLST) of the isolates using seven distinct loci (pntA, sucA, mreA, $g \operatorname{lm} U$, $c a i B$, tpiA, and $p f k B$ ) was performed as previously described [20]. The concatenated loci were compared to Leptospira sequence types (STs) available in the PubMLST database (https://pubmlst.org/leptospira/) using Maximum-Likelihood method by Bionumerics 7.6 (Applied Maths NV, Sint-Martens-Latem, Belgium).

\section{Virulence characterization}

A pure culture of each of the isolated strains was counted in a Petroff-Hausser chamber and $0.5 \mathrm{~mL}$ containing 108 leptospires was inoculated intraperitoneally in thirty-day-old male hamsters (one hamster for each isolate) to determine if the isolates would produce infection [21]. The animals were purchased at Anilab Animais de Laboratório Criação e Comércio, Paulínia, SP, and were bred strictly for research purposes. The hamsters were kept in individual $30 \times 20 \times 12 \mathrm{~cm}$ polypropylene cages lined with wood shavings; free fresh water and food was daily supplied. The animals were daily monitored for signs of acute leptospiral infection (prostration, ruff hair coat, jaundice, external hemorrhage and dehydration) and were immediately euthanized after presenting two or more clinical signs. The hamster's kidneys were aseptically removed, macerated, resuspended and inoculated in liquid $\mathrm{EMJH}$ medium for reisolation.

\section{Ethical considerations}

The euthanasia procedures conducted in the animal models were in strict accordance with the recommendations in the 
CONCEA (National Council for Control of Animal Experimentation), and consisted of intraperitoneal administration of xylasine/ketamine and isofluran, followed by the use of a $\mathrm{CO}_{2}$ chamber. Dogs presenting no response to treatment were euthanized by intravenous infusion of thiopental (75 mg/kg) and acepromazine $(0.05 \mathrm{mg} / \mathrm{kg})$, followed by the intravenous use of potassium chloride (dose-response curve - average of $10 \mathrm{ml}$ ). All euthanasia procedures were approved by the CEUAVET Committee, as stated in the Declarations section, and all efforts were made to minimize animal suffering.

\section{Statistical methods}

Univariate analysis was performed to describe average and standard deviation values for hematological and biochemical laboratory tests. These values were compared between leptospirosis confirmed cases (either through MAT or PCR) and non-confirmed cases using a T-test. The association of outcome with leptospirosis confirmed and non-confirmed groups was analyzed by a Chi-square test. All statistical analyses were performed in IBM SPSS Statistics 21. $P$-values of $<0.05$ were considered statistically significant.

\section{Results}

Of the 33 dogs included in the study, 18 (55.5\%) had MAT titers $\geq 100$, with titers ranging from 100 to 3200 (Table 1$)$. The predominant reactive serogroups were Icterohaemorrhagiae $(n=23)$, Australis $(n=7)$, Pomona $(n=4)$, Butembo $(n=4)$, and Castellonis $(n=3)$. Less common serogroups included Canicola, Shermani, Cynopteri $(n=2)$, Autumnalis $(n=1)$, Pyrogenes $(n=1)$ and Sejroe $(n=1)$.

Acute leptospirosis was diagnosed in eight dogs (24.2\%) by MAT: six dogs without a history of recent vaccination had titers $\geq 800$ in a single serum sample (dogs 3, 4, 11, 29, 31 and 32 - Table 1); additionally, prospective evaluation performed in seven dogs revealed seroconversion in two other dogs (dogs 15 and 30, see Additional file 1), which showed fourfold increase in MAT titers against Icterohaemorrhagiae serogroup (convalescent titers of 400 and 800, respectively). Overall, six dogs with MAT-confirmed leptospirosis had the highest titers against the Icterohaemorrhagiae serogroup; only one $\operatorname{dog}(\operatorname{dog} 4)$ had the highest titers against the Sejroe serogroup.

Leptospiral DNA was detected in 18 out of 33 animals; however, samples from four of these dogs (dogs 15, 17, 20 and 26) did not result in readable sequences after several sequencing attempts and therefore were not considered positive, leaving 14 PCR-positive dogs (42.4\% - Table 1). Positive yields were obtained from urine $(n=8)$, blood $(n=2)$ or both $(n=4)$. The $16 \mathrm{~S}$ rRNA phylogenetic analysis showed that the recovered sequences from all PCR-positive dogs were identified as L. interrogans
(Table 1), with high similarity (>99\%) to L. interrogans representatives (AY996798, AY996800). The recovered sequences were submitted to GenBank under accession numbers KX891325 - KX891333, MG640117 and MG640121.

The comparison between results from MAT-confirmed cases and PCR-positive dogs revealed that the infection could be identified exclusively by PCR in 10 dogs $(30.3 \%$; 14.6-46.0), exclusively by MAT in four dogs (12.1\%; 1.0-23.3; two seroconversions and two single samples) and by both tests in four dogs. The combined use of MAT and PCR was able to detect leptospiral infection in 18 dogs, with an overall prevalence of $54.5 \%$ (95\%CI: 37.6-71.5).

Clinical manifestations, laboratory findings and clinical outcome of the all dogs included in the study are presented in the Additional file 2. Clinical manifestations at presentation included vomiting (76\%), hyporexia/anorexia (97\%), diarrhea (33\%), dehydration (33\%) jaundice (57\%), bleeding disorders (21\%), oligodipsia, dysuria, anuria and oliguria (27\%), among other symptoms. Laboratory analyses revealed average BUN and CR levels of $427.54 \mathrm{mg} / \mathrm{dL}$ (SD 186.13) and $6.96 \mathrm{mg} / \mathrm{dL}$ (SD 4.99), respectively; ALT and ALP serum activity of 165.69 IU/L (SD 240.58) and 410.78 IU/L (454.9), respectively, $38.5 \% \mathrm{Ht}$ count (SD 10.70) and 21,954 $\mathrm{WBC} / \mu \mathrm{l}$ (SD 12.275). Clinical outcome of 20 dogs could be determined: 10 dogs survived after proper treatment and euthanasia/death occurred in 10 cases. Thirteen dogs did not show up for follow-up care and information regarding the clinical outcome could not be determined. The comparison between dogs with confirmed infection $(n=18)$ and symptomatic dogs with no confirmation of leptospiral infection $(n=15)$ revealed no significant differences $(p>0.05)$ in BUN/CR levels, ALT and ALP activity, $\mathrm{Ht}$ and WBC count or clinical outcome.

Leptospires were recovered from the urine samples of two dogs (dog 8, strain DU84; dog 24, strain DU100), which had PCR-positive results: only dog 8 had titers detectable by MAT, but serum titers were found to be below 800 (Table 1). Culturing as a single diagnostic strategy had a prevalence of $6.1 \%(0-14.2)$ and had no effect in the overall prevalence when combining all confirmatory tests (PCR, MAT and culturing) for the diagnosis of leptospirosis.

The MLST analysis of both isolated strains (DU84 and DU100) revealed ST 17 (Fig. 1), which characterizes $L$. interrogans serogroup Icterohaemorrhagiae according to a previously described protocol [20]. Serogrouping of the DU84 strain showed a strong and specific reaction against serovars Copenhageni (6400) and Icterohaemorrhagiae (12800); the DU100 strain also had specific reactions against these serovars (Copenhageni 12,800; Icterohaemorrhagiae 51,200), revealing that 
Table 1 Immunization records, PCR, culture, DNA sequencing and MAT results found in 33 dogs presenting clinical suspicion of leptospirosis treated at the Veterinary Hospital of University of São Paulo between 2013 and 2016

\begin{tabular}{|c|c|c|c|c|c|c|c|c|c|c|c|c|c|c|c|c|c|c|c|c|}
\hline \multirow[t]{2}{*}{ Dog } & \multicolumn{2}{|c|}{ PCR } & \multirow[t]{2}{*}{ DNA sequencing } & \multirow[t]{2}{*}{ Culture } & \multirow{2}{*}{$\begin{array}{l}\text { Vaccination } \\
\text { (<1 year })\end{array}$} & \multirow{2}{*}{$\begin{array}{c}\text { MAT } \\
(>100)\end{array}$} & \multicolumn{14}{|c|}{ MAT titration (serovar) } \\
\hline & Blood & Urine & & & & & Can & Po & Cas & Co & Ic & Py & $\mathrm{Br}$ & $\mathrm{Ha}$ & Wo & Sh & $\mathrm{Bu}$ & Aus & Cyn & Aut \\
\hline 1 & $N P$ & $(+)$ & L. interrogans & $(-)$ & $(+)$ & $(-)$ & - & - & - & - & - & - & - & - & - & - & - & - & - & - \\
\hline 2 & $(+)$ & $(+)$ & L. interrogans & $(-)$ & $(-)$ & $(+)$ & 400 & 200 & 200 & 100 & 200 & 200 & - & - & - & - & - & - & - & - \\
\hline 3 & $(-)$ & $(+)$ & L. interrogans & $(-)$ & $(-)$ & $(+)$ & - & 800 & - & 3200 & 3200 & - & 200 & - & - & - & - & - & - & - \\
\hline 4 & $(+)$ & $(+)$ & L. interrogans & $(-)$ & $(-)$ & $(+)$ & - & - & - & - & 100 & - & - & 800 & 800 & - & - & - & - & - \\
\hline 5 & NP & $(+)$ & L. interrogans & $(-)$ & $(-)$ & $(-)$ & - & - & - & - & - & - & - & - & - & - & - & - & - & - \\
\hline 6 & $(-)$ & $(-)$ & & $(-)$ & $(+)$ & $(+)$ & - & - & - & - & - & - & - & - & - & 200 & - & - & - & - \\
\hline 7 & NP & $(-)$ & & $(-)$ & $(-)$ & $(+)$ & - & - & - & - & - & - & - & - & - & - & - & - & 100 & - \\
\hline 8 & $(-)$ & $(+)$ & L. interrogans & $(+)$ & $(-)$ & $(+)$ & - & 200 & - & 400 & 400 & - & - & - & - & - & - & - & - & - \\
\hline 9 & $(-)$ & $(-)$ & & $(-)$ & $(+)$ & $(+)$ & 400 & - & - & 400 & 200 & - & 200 & - & - & - & 100 & 200 & - & - \\
\hline 10 & $(+)$ & $(-)$ & L. interrogans & $(-)$ & $(-)$ & $(-)$ & - & - & - & - & - & - & - & - & - & - & - & - & - & - \\
\hline 11 & $(-)$ & $(-)$ & & $(-)$ & $(-)$ & $(+)$ & - & - & - & 800 & 400 & - & - & - & - & - & - & - & - & - \\
\hline 12 & $(-)$ & $(+)$ & L. interrogans & $(-)$ & $(+)$ & $(+)$ & - & - & - & - & - & - & 400 & - & - & - & - & - & 400 & - \\
\hline 13 & $(-)$ & $(-)$ & & $(-)$ & $(-)$ & $(-)$ & - & - & - & - & - & - & - & - & - & - & - & - & - & - \\
\hline${ }^{a} 14$ & $(-)$ & $(-)$ & & $(-)$ & $(+)$ & $(+)$ & - & 100 & - & - & - & - & - & - & - & - & - & - & - & 100 \\
\hline${ }^{\mathrm{a}} 15$ & $(-)$ & $(+)$ & - & $(-)$ & $(-)$ & $(-)$ & - & - & - & - & - & - & - & - & - & - & - & - & - & - \\
\hline 16 & $(+)$ & $(-)$ & L. interrogans & $(-)$ & $(-)$ & $(+)$ & - & - & - & 400 & 200 & - & - & - & - & - & 200 & - & - & - \\
\hline${ }^{a} 17$ & $(+)$ & $(+)$ & - & $(-)$ & $(-)$ & $(-)$ & - & - & - & - & - & - & - & - & - & - & - & - & - & - \\
\hline 18 & $(-)$ & $(-)$ & & $(-)$ & $(+)$ & $(-)$ & - & - & - & - & - & - & - & - & - & - & - & - & - & - \\
\hline 19 & $(-)$ & $(-)$ & & $(-)$ & $(-)$ & $(-)$ & - & - & - & - & - & - & - & - & - & - & - & - & - & - \\
\hline 20 & $(-)$ & $(+)$ & - & $(-)$ & $(-)$ & $(+)$ & - & - & - & 400 & 400 & - & - & - & - & - & - & 400 & - & - \\
\hline 21 & $(-)$ & $(-)$ & & $(-)$ & $(-)$ & $(-)$ & - & - & - & - & - & - & - & - & - & - & - & - & - & - \\
\hline${ }^{\mathrm{a}} 22$ & $(-)$ & $(+)$ & L. interrogans & $(-)$ & $(-)$ & $(-)$ & - & - & - & - & - & - & - & - & - & - & - & - & - & - \\
\hline 23 & $(-)$ & $(-)$ & & $(-)$ & $(+)$ & $(+)$ & - & - & - & 200 & - & - & - & - & - & - & - & - & - & - \\
\hline${ }^{\mathrm{a}} 24$ & $(-)$ & $(+)$ & L. interrogans & $(+)$ & $(+)$ & $(-)$ & - & - & - & - & - & - & - & - & - & - & - & - & - & - \\
\hline${ }^{\mathrm{a}} 25$ & $(-)$ & $(-)$ & & $(-)$ & $(-)$ & $(-)$ & - & - & - & - & - & - & - & - & - & - & - & - & - & - \\
\hline 26 & $(+)$ & $(+)$ & - & $(-)$ & $(+)$ & $(-)$ & - & - & - & - & - & - & - & - & - & - & - & - & - & - \\
\hline 27 & $(-)$ & $(-)$ & & $(-)$ & $(-)$ & $(-)$ & - & - & - & - & - & - & - & - & - & - & - & - & - & - \\
\hline 28 & $(-)$ & $(-)$ & & $(-)$ & $(-)$ & $(-)$ & - & - & - & - & - & - & - & - & - & - & - & - & - & - \\
\hline 29 & $(-)$ & $(-)$ & & $(-)$ & $(-)$ & $(+)$ & - & - & 100 & 800 & 400 & - & - & - & - & 400 & - & 400 & - & - \\
\hline${ }^{a} 30$ & $(-)$ & $(-)$ & & $(-)$ & $(-)$ & $(+)$ & - & - & - & 200 & 200 & - & - & - & - & - & - & - & - & - \\
\hline 31 & $(-)$ & $(+)$ & L. interrogans & $(-)$ & $(-)$ & $(+)$ & - & - & 800 & - & - & - & - & - & - & - & - & - & - & - \\
\hline 32 & $(+)$ & $(+)$ & L. interrogans & $(-)$ & $(-)$ & $(+)$ & - & - & - & 1600 & - & - & - & - & - & - & 200 & 800 & - & - \\
\hline 33 & $(+)$ & $(+)$ & L. interrogans & $(-)$ & $(-)$ & $(+)$ & - & - & - & 200 & 100 & - & - & - & - & - & 100 & - & - & - \\
\hline
\end{tabular}

${ }^{a}$ Dogs included in the prospective evaluation

NP not performed, Can Canicola, Po Pomona, Cas Castellonis, Co Copenhageni, Ic Icterohaemorrhagiae, Py Pyrogenes, Br Bratislava, Ha Hardjo, Wo Wollfii, Sh Shermani, Bu Butembo, Aus Australis, Cyn Cynopteri, Aut Autumnalis

both isolated strains belong to the Icterohaemorrhagiae serogroup.

The inoculation of the isolates in the hamster model produced acute and intense clinical manifestations of leptospirosis. The hamsters developed acute lethal infection within six days post-inoculation, and macroscopic alterations included epistaxis, generalized petechial stains, pulmonary/liver congestion and pulmonary hemorrhage.
Leptospires were successfully recovered from the kidney and liver tissues of both hamsters after euthanasia, thus indicating leptospiral infection as the cause of disease.

\section{Discussion}

The use of MAT and PCR (with further DNA sequencing) as independent diagnostic strategies enabled the identification of eight (24.2\%) and 14 (42.4\%) dogs with leptospiral 


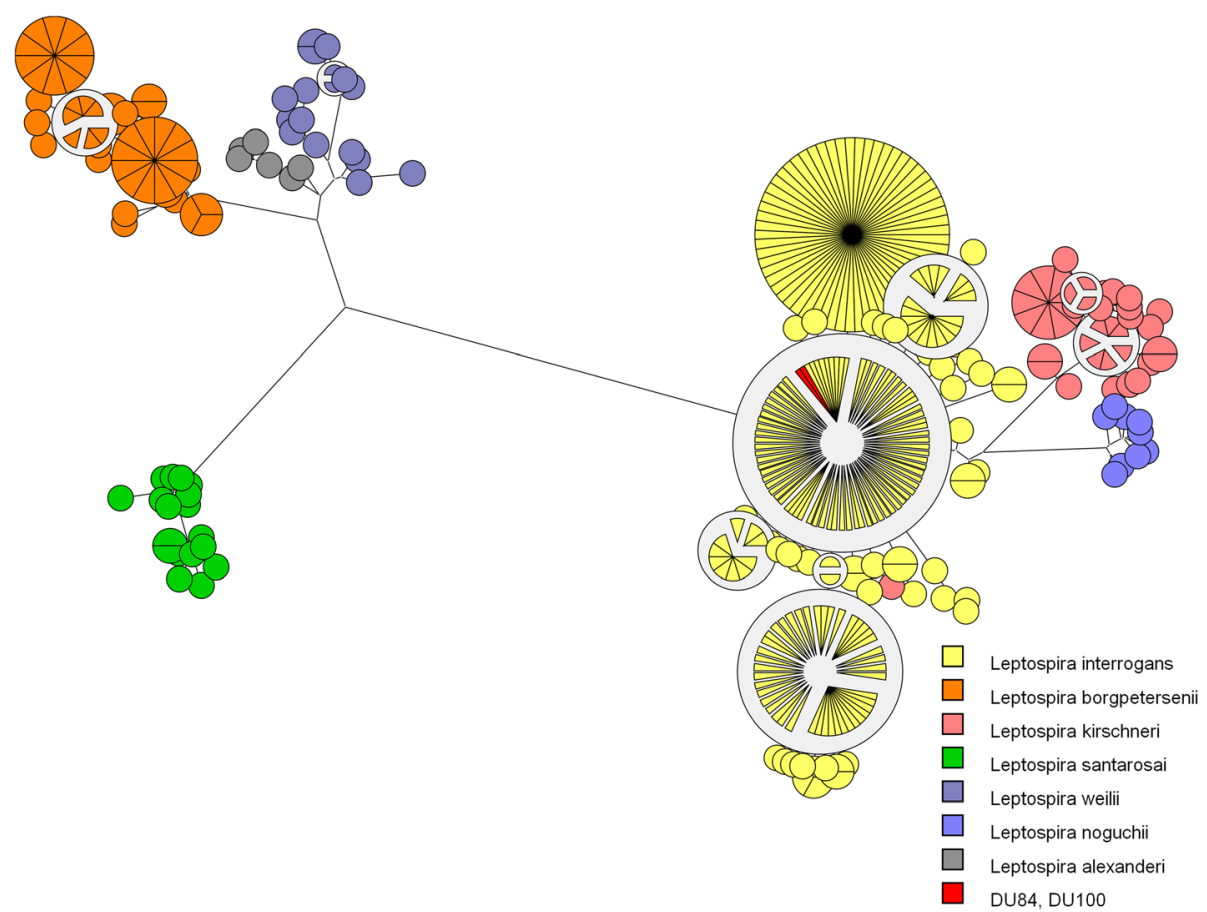

Fig. 1 MLST analysis of the DU84 and DU100 strains. The Maximum-likelihood tree was based on the concatenated sequences of the seven loci for the 229 available Leptospira STs

infection, respectively, while the association of both tests increased the diagnosis of leptospirosis in clinically suspected cases, thus confirming the infection in 18 (54.5\%) out of the 33 suspected dogs included in the study.

Although PCR was able to identify a higher proportion of infected dogs than MAT, the high number of dogs that follow-up care was discontinued and the high mortality/euthanasia rates found in the studied population has limited a more appropriate comparison between PCR and MAT results. It is usually recommended that the diagnosis of acute infection by MAT should be based on testing paired samples, collected 7 to 14 days apart, in order to detect at least a fourfold increase in agglutinating antibodies against Leptospira [1]. Only 7 out of 33 dogs could be prospectively evaluated, and serum samples with more than 7-day interval between acute and convalescent phases were obtained only from five dogs, including both dogs in which seroconversion was detected. Moreover, the cut off value of 800 adopted in the present study, which has been previously suggested to increase the specificity of MAT [5], and the natural delay to produce an adaptive serologic response after infection, may have led to false-negative results when testing a single serum sample by MAT. Even in face of such limitations, active leptospiral infection was determined in four dogs exclusively by MAT, while PCR was able to detect 10 infected dogs at clinical presentation that a single MAT sample evaluation could not, reinforcing that the use of multiple tests is beneficial for improving the diagnosis of canine leptospirosis in practical situations in which the clinical outcome and the possibility of follow-up care are uncertain [6].

These results are markedly different from those reported by Fraune et al. [5], who found no significant benefit in the use of PCR in relation to MAT for the early diagnosis of acute canine leptospirosis. On the other hand, our results are in agreement with the findings reported by Harkin et al. [6, 11], who found a sensitivity of $100 \%$ and specificity of $88.3 \%$ when testing a leptospiral-specific PCR assay with urine samples from dogs with clinical suspicion of leptospirosis. It is important to emphasize that the application of PCR in a clinical setting, notably when using urine specimens, may provide false-positive results [22], and the association with DNA sequencing, as performed in the present study, is highly recommended to provide more reliable results for proper comparison with other diagnostic techniques. Most dogs diagnosed by PCR and DNA sequencing were identified using urine samples, and even though the detection of leptospiral DNA in urine specimens taken from dogs with multiple signs of leptospirosis is highly suggestive of acute leptospiral infection, it may not distinguish dogs with acute infection from those with chronic renal carriage of leptospires associated with other underlying diseases causing clinical manifestations similar to leptospirosis. Instead, the detection of leptospiral DNA from 
blood and serum samples must be considered a more reliable strategy to diagnose acute leptospirosis in dogs by molecular methods. Our results have also shown no distinction in laboratory findings and clinical outcome between confirmed and non-confirmed cases of leptospirosis, highlighting the non-specificity of clinical and laboratory evaluations for the diagnosis of the disease.

Both isolated strains could be characterized as L. interrogans serogroup Icterohaemorrhagiae and were shown to be pathogenic in a hamster model. The overall serological pattern found in the population studied indicates that the suspected dogs admitted to the veterinary hospital of the University of São Paulo, an ambulatory service that provides care for dogs from different regions of São Paulo city, are highly exposed to the Icterohaemorrhagiae serogroup. The isolation of serogroup Icterohaemorrhagiae from dogs with leptospirosis has been previously described in Brazil [21, 23], and previous serological surveys have consistently shown Icterohaemorrhagiae as the most reactive serogroup in dogs suspected of leptospirosis [15, 24-27]. Interestingly, the serological profile of human subjects suspected of leptospiral infection also indicates Icterohaemorrhagiae/Copenhageni as the main causative agents attributed to human infection [28-31], and most strains recovered from human patients with leptospirosis in Brazil were characterized as Icterohaemorrhagiae $[29,32]$. Our findings corroborate the hypothesis that both dogs and humans are exposed to environmental contamination promoted by rodents [33], notably the brown rat (Rattus norvegicus), which was implicated as the main reservoir host of Icterohaemorrhagiae/ Copenhageni serovars in urban areas from Brazil and other locations $[34,35]$.

Serological findings also revealed that leptospiral strains belonging to the Sejroe serogroup might be associated with acute leptospiral infection in dogs. This serogroup has been previously described as a causative agent of canine leptospirosis [36], and it was recently recovered from an asymptomatic dog in São Paulo city [12], thus indicating that Sejroe strains are actually circulating among dog populations in Brazil. In contrast, MAT titration against Canicola was only found in two dogs, which had low titers against this serogroup. Canicola strains are frequently isolated from dogs in Brazil and other locations [15, 16, 37], although serological evidence of Canicola infection is not often observed [38]. A previous study including dogs suspected of clinical leptospirosis conducted by our group between 2008 and 2012 found that even though most dogs reacted against serogroup Icterohaemorrhagiae, Canicola strains could still be recovered from three symptomatic dogs which had no MAT titers against this serovar [15]. All sequences from PCR-positive dogs could be identified as $L$. interrogans in this study, yet molecular characterization using single-gene sequencing methods has poor discriminatory power to distinguish among leptospires at a serovar/serogroup level [39], and infection caused by Canicola, although possible, could not be confirmed.

\section{Conclusions}

Our results suggest that the use of multiple tests is essential for a more accurate and sensitive diagnosis of acute leptospirosis in dogs in a clinical setting. The results also suggest that despite the rising incidence of new serovars affecting dogs in different locations [3], mostly attributed to the extensive use of multivalent vaccines containing few representative serovars, and the increased contact between dogs and wildlife from rural-urban interface regions [5, 40, 41], the Icterohaemorrhagiae serogroup is still a major causative agent of canine leptospirosis in São Paulo, Brazil. Proper characterization of leptospiral isolates remain a crucial bottleneck to access the role of particular Leptospira strains in the epidemiology of canine leptospirosis and may provide evidence-based knowledge to support the development and commercialization of multivalent vaccines containing serovars that are circulating among local populations.

\section{Additional files}

Additional file 1: Supplementary data from seven dogs revaluated after presenting clinical suspicion of leptospirosis. Additional file 1 shows data regarding immunization records, $P C R$, culture, DNA sequencing, MAT results and laboratory findings from the seven dogs that could be revaluated after presenting clinical suspicion of leptospirosis. (DOCX 144 kb)

Additional file 2: Supplementary data regarding clinical and laboratorial tests performed in the evaluation of the 33 suspected dogs included in the study. Additional file 1 shows confirmatory results from MAT, PCR and culture tests, as well as clinical outcome and clinical/laboratorial findings found in the first evaluation of each of the 33 suspected dogs included in the study. (DOCX $158 \mathrm{~kb}$ )

\section{Abbreviations}

ALP: Alkaline phosphatase; ALT: Alanine aminotransferase; BUN: Blood urea nitrogen; CR: Creatinine; EDTA: Ethylenediamine tetraacetic acid;

Ht: Hematocrit; MAT: Microscopic agglutination test; MLST: Multilocus Sequence Typing; PCR: Polymerase chain reaction; WBC: White blood cell

\section{Acknowledgements}

We would like to thank the LZB, LABMAS and Hovet staff for their full support, especially Cláudia Strangiollo, Samantha Miyashiro, Khadine Kanayama, Bruna Coelho, Andrea Correa, Vera Wirthl, Sheila Oliveira, Sueli Taniwaki, Zenaide Moraes, and Gisele Oliveira. We also would like to thank Ana Paula Loureiro from Universidade Federal Fluminense (UFF) for serogrouping the isolates.

\section{Funding}

This work was supported by Fundação de Amparo à Pesquisa do Estado de São Paulo (FAPESP - 2012/14681-7); B.A.M. is recipient of FAPESP (2012/13022-0) and a CNPq (Conselho Nacional de Desenvolvimento Científico e Tecnológico) PhD fellowship (164284/2014); L.Z.M. is recipient of a PhD fellowship from FAPESP (2013/17136-2); A.M.M., M.K.H., M.B.H. and W.L are CNPq research fellows.

Availability of data and materials

The datasets generated and/or analysed during the current study are not publicly available due to the confidentiality agreement with the participants (dog owners), but are available from the corresponding author on reasonable request. 


\section{Authors' contributions}

(BAM, BFT, MKH, MSP, LZM and AGAG) made substantial contributions to the conception of the study design, acquisition, analysis and interpretation of data; $(\mathrm{MBH}, \mathrm{WL}, \mathrm{AMM})$ contributed to the data analysis and by revising it critically for important intellectual content; Each author have participated sufficiently in the work to take public responsibility for appropriate portions of the content; and (MBH, BAM) agreed to be accountable for all aspects of the work in ensuring that questions related to the accuracy or integrity of any part of the work are appropriately investigated and resolved. All authors read and approved the final manuscript.

\section{Ethics approval and consent to participate}

The Ethics Committee of the School of Veterinary Medicine and Animal Science, University of São Paulo (protocols 2706/2012 and 2,406,140,614) approved all procedures involving animal manipulation in the current study. All clinical and laboratory procedures, including euthanasia of dogs presenting no response to treatment, were approved by the dog owners with a written consent.

\section{Consent for publication}

Not applicable

\section{Competing interests}

The authors declare that they have no competing interests.

\section{Publisher's Note}

Springer Nature remains neutral with regard to jurisdictional claims in published maps and institutional affiliations.

\section{Author details}

'Departamento de Clínica Médica (Department of Veterinary Clinics), Faculdade de Medicina Veterinária e Zootecnia (School of Veterinary Medicine and Animal Science), Universidade de São Paulo (University of São Paulo), São Paulo, SP 05508-270, Brazil. ²Departamento de Medicina Veterinária Preventiva e Saúde Animal (Department of Veterinary Preventive Medicine and Animal Health), Faculdade de Medicina Veterinária e Zootecnia (School of Veterinary Medicine and Animal Science), Universidade de São Paulo (University of São Paulo), São Paulo, SP 05508-270, Brazil. ${ }^{3}$ Departamento de Microbiologia e Parasitologia (Department of Microbiology and Parasitology), Universidade Federal Fluminense, Niterói, R 24210-130, Brazil.

\section{Received: 1 January 2018 Accepted: 9 July 2018}

\section{Published online: 17 July 2018}

\section{References}

1. Schuller S, Francey T, Hartmann K, Hugonnard M, Kohn B, Nally JE, Sykes J. European consensus statement on leptospirosis in dogs and cats. J Small Anim Pract. 2015:56:159-79.

2. Azocar-Aedo L, Monti G. Meta-analyses of factors associated with leptospirosis in domestic dogs. Zoonoses Public Health. 2016;63:328-36.

3. Hartskeerl RA, Collares-Pereira M, Ellis WA. Emergence, control and re-emerging leptospirosis: dynamics of infection in the changing world. Clin Microbiol Infect. 2011:17:494-501.

4. Andre-Fontaine G. Canine leptospirosis - do we have a problem? Vet Microbiol. 2006;117:19-24.

5. Fraune CK, Schweighauser A, Francey T. Evaluation of the diagnostic value of serologic microagglutination testing and a polymerase chain reaction assay for diagnosis of acute leptospirosis in dogs in a referral center. J Am Vet Med Assoc. 2013:242:1373-80.

6. Harkin KR, Roshto YM, Sullivan JT, Purvis TJ, Chengappa MM. Comparison of polymerase chain reaction assay, bacteriologic culture, and serologic testing in assessment of prevalence of urinary shedding of leptospires in dogs. J Am Vet Med Assoc. 2003;222:1230-3.

7. Penna B, Marassi CD, Libonati H, Narduche L, Lilenbaum W, Bourhy P. Diagnostic accuracy of an in-house ELISA using the intermediate species Leptospira fainei as antigen for diagnosis of acute leptospirosis in dogs. Comp Immunol Microbiol Infect Dis. 2017;50:13-5.

8. Gloor Cl, Schweighauser A, Francey T, Rodriguez-Campos S, Vidondo B, Bigler B, Schuller S. Diagnostic value of two commercial chromatographic "patient-side" tests in the diagnosis of acute canine leptospirosis. J Small Anim Pract. 2017:58:154-61.

9. Schuller S, Callanan JJ, Worrall S, Francey T, Schweighauser A, Kohn B, Klopfleisch R, Posthaus H, Nally JE. Immunohistochemical detection of IgM and IgG in lung tissue of dogs with leptospiral pulmonary haemorrhage syndrome (LPHS). Comp Immunol Microbiol Infect Dis. 2015;40:47-53.

10. Levett PN. Usefulness of serologic analysis as a predictor of the infecting serovar in patients with severe leptospirosis. Clin Infect Dis. 2003:36:447-52.

11. Harkin KR, Roshto YM, Sullivan JT. Clinical application of a polymerase chain reaction assay for diagnosis of leptospirosis in dogs. J Am Vet Med Assoc. 2003;222:1224-9.

12. Miotto BA, Moreno LZ, Guilloux AGA, de Sousa GO, Loureiro AP, Moreno AM, Lilenbaum W, Vasconcellos SA, Heinemann MB, Hagiwara MK. Molecular and serological characterization of the first Leptospira santarosal strain isolated from a dog. Acta Trop. 2016:162:1-4.

13. da Cunha CEP, Felix SR, Neto ACPS, Campello-Felix A, Kremer FS, Monte LG, Amaral MG, de Oliveira Nobre M, da Silva ÉF, Hartleben CP. McBride AJ, Dellagostin OA. Infection with Leptospira kirschneri serovar Mozdok: first report from the southern hemisphere. Am J Trop Med Hyg. 2016;94:519-21.

14. Koizumi N, Muto MM, Akachi S, Okano S, Yamamoto S, Horikawa K, Harada S, Funatsumaru S, Ohnishi M. Molecular and serological investigation of Leptospira and leptospirosis in dogs in Japan. J Med Microbiol. 2013;62:630-6.

15. Rodrigues AMA, Vasconcellos SA, de Moraes ZM, Hagiwara MK. Isolation of Leptospira Spp. from dogs with clinical suspect of leptospirosis in São Paulo (Brazil). Acta Sci Vet. 2007;2:705-6.

16. Miraglia F, Morais ZM, Dellagostin OA, Seixas FK, Freitas JC, Zacarias FG, Delbem AC, Ferreira TS, Souza GO, Hartskeerl RA, Vasconcellos SA, Moreno AM. Molecular and serological characterization of Leptospira interrogans serovar Canicola isolated from dogs, swine, and bovine in Brazil. Trop Anim Health Prod. 2012:45:117-21.

17. World Organization for Animal Health. Leptospirosis: Guidance for Diagnosis, Surveillance and Control; 2012. p. 57-72.

18. Mérien F, Amouriaux P, Perolat P, Baranton G, Saint Girons I. Polymerase chain reaction for detection of Leptospira spp. in clinical samples. J Clin Microbiol. 1992;30:2219-24.

19. Dikken H, Kmety E. Chapter VIII serological typing methods of leptospires. In: TBAJR N, editor. Methods Microbiol Academic Press; 1978. p. 259-307T2.

20. Boonsilp S, Thaipadungpanit J, Amornchai P, Wuthiekanun V, Chierakul W, Limmathurotsakul D, Day NP, Peacock SJ. Molecular detection and speciation of pathogenic Leptospira spp. in blood from patients with culture-negative leptospirosis. BMC Infect Dis. 2011;11:338.

21. Jorge S, Monte LG, Oliveira NR, Collares TF, Roloff BC, Gomes CK, Hartwig DD, Dellagostin OA, Hartleben CP. Phenotypic and molecular characterization of Leptospira interrogans isolated from Canis familiaris in southern Brazil. Curr Microbiol. 2015:71:496-500.

22. Fink JM, Moore GE, Landau R, Vemulapalli R. Evaluation of three 5 ' exonucleasebased real-time polymerase chain reaction assays for detection of pathogenic Leptospira species in canine urine. J Vet Diagn Investig. 2015;27:159-66.

23. Miraglia F, Matsuo M, Morais ZM, Dellagostin OA, Seixas FK, Freitas JC, Hartskeerl R, Moreno LZ, Costa BL, Souza GO, Vasconcellos SA, Moreno AM. Molecular characterization, serotyping, and antibiotic susceptibility profile of Leptospira interrogans serovar Copenhageni isolates from Brazil. Diag Microbiol Infec Dis. 2013;77:195-9.

24. Santana WJ, Santos AS, Azevedo ZFT, Macedo JO, Solcá M, Camaroti P, Tourinho M, fraga DBM, Cerqueira RB, Mcbride FWC. Levantamento epidemiológico da leptospirose canina em animais atendidos no Hospital Veterinário da Unime na cidade de Lauro de Freitas, Bahia. In: Congresso Brasileiro De Medicina Veterinária, 35; Conbravet, 5; Congresso De Medicina Veterinária Do Cone Sul, 2008. Gramado: Anais; 2008.

25. Freire IMA, Varges RG, Gomes YN, Pombo CR, Lilembaun W. Distribuição dos serovares de Leptospira em caninos clinicamente suspeitos no Rio De Janeiro. R Bras Ci Vet. 2007:14:83-5.

26. Morikawa VM, Bier D, Pellizzaro M, Ullmann LS, Paploski IAD, Kikuti M, Langoni H, Biondo AW, Molento MB. Seroprevalence and seroincidence of Leptospira infection in dogs during a one-year period in an endemic urban area in southern Brazil. Rev Soc Bras Med Trop. 2015:48:50-5.

27. Querino AMV, Delbem ÁCB, de Oliveira RC, Silva FGD, Müller EE, Freire RL, Freitas JC. Fatores de risco associados à leptospirose em cães do município de Londrina-PR. Sem Ci Agr. 2003;24:27-34.

28. Felzemburgh RDM, Ribeiro GS, Costa F, Reis RB, Hagan JE, Melendez AX Fraga D, Santana FS, Mohr S, dos Santos BL, Silva AQ, Santos AC, Ravines RR, 
Tassinari WS, Carvalho MS, Reis MG, Ko Al. Prospective study of leptospirosis transmission in an urban slum community: role of poor environment in repeated exposures to the Leptospira agent. PLoS Negl Trop Dis. 2014;8:e2927-9.

29. Blanco RM, Romero EC. Fifteen years of human leptospirosis in São Paulo, Brazil. J Epidemiolol Res. 2015;2:56-6.

30. Romero EC, Bernardo CCDM, Yasuda PH. Human leptospirosis: a twentynine-year serological study in São Paulo, Brazil. Rev Inst Med trop S Paulo. 2003;45:245-8.

31. Oliveira MAA, Leal ÉA, Correia MA, Filho JCS, Dias RS, Serufo JC. Human leptospirosis: occurrence of serovars of Leptospira spp. in the state of Minas Gerais, Brazil, from 2008 to 2012. Braz J Microbiol. 2017:48:483-8.

32. Romero EC, Blanco RM, Galloway RL. Analysis of multilocus sequence typing for identification of Leptospira isolates in Brazil. J Clin Microbiol. 2011;49:3940-2.

33. Martins G, Penna B, Lilenbaum W. The dog in the transmission of human leptospirosis under tropical conditions: victim or villain? Epidemiol Infect. 2012;140:207-8

34. de Faria MT, Calderwood MS, Athanazio DA, McBride AJA, Hartskeerl RA, Pereira MM, Ko Al, Reis MG. Carriage of Leptospira interrogans among domestic rats from an urban setting highly endemic for leptospirosis in Brazil. Acta Trop. 2008;108:1-5.

35. Ko Al, Galvão Reis $M$, Ribeiro Dourado $C M$, Johnson WD, Riley LW. Urban epidemic of severe leptospirosis in Brazil. Lancet. 1999;354:820-5.

36. Rühl-Fehlert Cl, Brem S, Feller W, Kopp H, Meyer P, Rinke M. Clinical, microbiological and pathological observations in laboratory beagle dogs infected with leptospires of the serogroup Sejroe. Exp Toxicol Pathol. 2000;52:201-7.

37. Brod CS, Aleixo J, Jouglard SDD, Fernandes CPH, Teixeira JLR, Dellagostin OA. Evidence of dog as a reservoir for human leptospirosis: a serovar isolation, molecular characterization and its use in a serological survey. Rev Soc Bras Med Trop. 2005;38:294-300.

38. da Silva Pinto P, Libonati H, Penna B, Lilenbaum W. A systematic review on the microscopic agglutination test seroepidemiology of bovine leptospirosis in Latin America. Trop Anim Health Prod. 2016:48:239-48.

39. Cerqueira GM, Picardeau M. A century of Leptospira strain typing. Infec Genet Evol. 2009:9:760-8.

40. Ellis WA. Control of canine leptospirosis in Europe: time for a change? Vet Rec. 2010;167:602-5

41. Gautam R, Guptill LF, Wu CC, Potter A, Moore GE. Spatial and spatio-temporal clustering of overall and serovar-specific Leptospira microscopic agglutination test (MAT) seropositivity among dogs in the United States from 2000 through 2007. Prev Vet Med. 2010:96:122-31.

Ready to submit your research? Choose BMC and benefit from:

- fast, convenient online submission

- thorough peer review by experienced researchers in your field

- rapid publication on acceptance

- support for research data, including large and complex data types

- gold Open Access which fosters wider collaboration and increased citations

- maximum visibility for your research: over $100 \mathrm{M}$ website views per year

At $\mathrm{BMC}$, research is always in progress.

Learn more biomedcentral.com/submissions 